\title{
Diabetes Sweeping Rural Areas: Findings from Community Based Study in Rural Agra, India
}

\author{
Vishal Agarwal, Geetu Singh, Sunil Kumar Misra
}

\section{Vishal Agarwal, Geetu Singh, Sunil Kumar Misra}

Department of Community Medicine, SN Medical College, Agra, Uttar Pradesh, INDIA.

\section{Correspondence \\ Geetu Singh \\ Lecturer/Assistant Professor, Department of Community Medicine, S N Medical College, Agra, Uttar Pradesh, INDIA. \\ Mobile no: 07376043771 \\ Email: geetu.singh1701@gmail.com \\ History \\ - Submission Date: 08-08-2017 \\ - Revised Date: 06-07-2017 \\ - Accepted Date: 10-11-2017}

\section{DOI : 10.5530/ijmedph.2017.4.43}

\section{Article Available online}

http://www.ijmedph.org/v7/i4

\section{Copyright}

(C) 2017 Phcog.Net. This is an openaccess article distributed under the terms of the Creative Commons Attribution 4.0 International license.

\begin{abstract}
Introduction: The International Diabetes Federation (IDF) showed that nearly 7 crore people in India were suffering from diabetes in 2015 and this number is projected to be 12.5 crore by 2040. India's economic boom has been accompanied by a dramatic upsurge of diabetes. Globalization of unhealthy lifestyles are closing the gap between urban and rural diabetes. So it has become important to estimate the diabetes prevalence and risk factors in rural Agra, India where no community based data was available. Material and Methods: This community based cross-sectional study was carried out in rural Agra from June 2013 to 2014. The sample size was calculated to 1209. Data was collected using a structured and pre-tested questionnaire while fasting blood glucose measured with the help of Glucocard - Vital Glucometer. The data was compiled and statistically analyzed using SPSS-22 software. Results: The prevalence of Diabetes Mellitus in rural Agra was found to be $7 \%$ with a diagnostic gap of $37 \%$. Prevalence of Diabetes was observed significantly associated with the age, occupation and socioeconomic status. Prevalence of Diabetes Mellitus was significantly more in people with higher Body mass index $(13.3 \%)$, centrally obesity $(10.3 \%)$ and higher Waist Hip Ratio $(8.4 \%)$ than with normal BMI (4.4\%), non-obese (4.2\%) and normal WHR category (1.6\%). On multiple logistic regression age, hypertension, $\mathrm{BMI}$ and WHR contribute as risk factors for developing Diabetes mellitus. Conclusion: As evident from findings diabetes is becoming common in rural population also, adding to the problem is poor awareness. Health care systems should be strengthened for early detection and effective treatment of disease.

Key words: Diabetes, Prevelance, Risk factors, Diagnostic gap, Prevalence, Body mass index.
\end{abstract}

\section{INTRODUCTION}

Diabetes mellitus as called madhumeha (sweet urine disease) has its citation thousands of year back in "charaka samhita." Present in every country and affecting millions around globe, Kelly west often called father of diabetes epidemiology labeled it as epidemic way back in $1921 .^{2}$ WHO with diabetes as World health day theme in 2016 highlighted this growing problem stating " 422 million people have diabetes around the world. That's almost four times than in 1980!!” India has around 65 million diabetics (Lancet 2016)...40\% of Delhiites are diabetic (ET health news Aug 2016)...five out of the top 10 largest-selling drugs in the country are now anti-diabetes (AICOD July 2016)...prevalence of adult diabetes in India was recorded at $9.5 \%$ in 2015 against a global average of 9\% (global nutrition report 2016)... all these news are a grim reminder of the growing incidence of lifestyle diseases in developing countries.

The International Diabetes Federation (IDF) showed that nearly 7 crore people in India were suffering from diabetes in 2015 and if changes in lifestyle and food habits are not made this number will be 12.5 crore by 2040 . This paper, based on data from 751 studies, showed that the prevalence of diabetes has increased $80 \%$ in women and more than doubled in men in the country. ${ }^{3}$ India's economic boom has been accompanied by a dramatic upsurge of diabetes. Some issues are troubling country -double burden problem (it is housing maximum stunted children and at 7 crore, India is among top 3 countries with highest diabetic population), distressing fact that now it is appearing even at lower BMI and lower age, ${ }^{4}$ though Universal health coverage (UHC) is fuelling but data shows cardiovascular disease patients in India spent $30 \%$ of their annual family income on related healthcare.

These figures in millions and doubling rate is quite alarming, same as the risk factors as the so called status symbol tags are now becoming stress symbols. Ever growing threat of over nutrition, obesity and diabetes, rapid cultural and social changes, ageing population, increasing urbanization, dietary changes, reduced physical activity and unhealthy behaviors. Globalization of unhealthy lifestyles are closing the gap between urban and rural diabetes. Nearly $68.84 \%$ of India resides in rural areas (census 2011). Recent figures showed surprisingly increased rates in rural areas. The prevalence in rural areas of the Chandigarh, Tamil Nadu, Maharashtra and Jharkhand, was $8.3 \%$, $7.8 \%, 6.5 \%$ and $3 \%$ respectively. ${ }^{5}$ Lack of area specific data in state of Uttar Pradesh and wave of westernization lifestyles and food engulfing people in rural area also, 
it has become important to measure the prevalence, socio-demographic factors and risk factors associated with it.

\section{MATERIAL AND METHOD}

This study was carried out in the field practice area of rural health training center (RHTC) Saiyan, attached to Department of community medicine, S.N. Medical College, Agra from July 2013 to July 2014. Due to familiarity with the area and frequent visits we selected four by random sampling villages from Saiyan block. Four villages were selected by random sampling and all population above 30 years presented on the day of survey and willing to participate were taken for the study. House to house survey was done. The total number of subjects thus surveyed from four villages was 1209. Data was collected using a structured and pre-tested questionnaire. The questionnaire was translated into the local language. The subjects were briefed about the procedure of the investigation and a repeat visit was made on the consecutive day early in the morning to measure fasting capillary blood glucose with the help of Glucocard-Vital Glucometer. Physical activity was measured using International Physical Activity Questionnaire (IPAQ). Activities are classified as vigorous and moderate physical activities. The total duration of physical activity, per week, is calculated to the nearest minute; metabolic equivalents (MET) are calculated. The data was compiled and statistically analyzed using SPSS-22 software.

Definitions and Diagnostic Criteria: Diabetes Mellitus was defined on criteria laid by WHO i.e. Fasting Plasma Glucose $\geqq 126 \mathrm{mg} / \mathrm{dl}$, for Impaired Fasting Glucose (IFG) $=110-125 \mathrm{mg} / \mathrm{dl}$ and known Diabetics under treatment. ${ }^{6}$

\section{RESULTS}

The prevalence of Diabetes Mellitus in rural Agra was found to be 7\%. Almost one third (2.7\%) were newly diagnosed while the remaining were known diabetics; thus giving a diagnostic gap of $37 \%$. (Table 1). The standardized prevalence (standardized with census 2011 population) of Diabetes Mellitus was calculated to be $7.7 \%$. Prevalence of Diabetes was observed significantly associated with the age, occupation, socioeconomic status. The difference is statistically significant between all groups combined and laborers of participants. Diabetes is not choosing caste as it was found insignificant. The prevalence of diabetes was highest in class I statistically significant difference between class I and class IV \& V. (Table 2,3,4)

Prevalence of Impaired fasting glucose was found to be $6.4 \%$ using WHO criteria and almost four times (26.6\%) using ADA criteria. (Table 5) Prevalence of Diabetes Mellitus was more in People with higher BMI (13.3\%), centrally obesity (10.3\%) and higher Waist Hip Ratio (8.4\%) than with normal BMI (4.4\%), non-obese (4.2\%) and normal WHR category (1.6\%). (Table 6,7,8,9) Among Hypertensives, diabetes was found to be higher as compared to normotensive and the difference is statistically significant. (Table 10). Prevalence of diabetes decreased significantly from $10.7 \%$ among those with low physical activity to $4.4 \%$ among those having vigorous activity. (Table 11) Variables significant in univariate analysis were included for multiple logistic regression-age, hypertension, BMI and WHR contribute as risk factors for developing Diabetes mellitus in this study. (Table 12)

\section{DISCUSSION}

India, the second most populous country of the world, has been severely affected by the global diabetes epidemic. There is clear evidence to show that diabetes prevalence is rapidly increasing, both in urban and rural India. This study for rural Agra found prevalence of diabetes mellitus to be $7.0 \%$ which is in accordance with a multicentric study, ICMR-
INDIAB (2011) which reported prevalence as $6.5 \%, 7.8 \%$ and $8.3 \%$ in rural areas of Maharashtra, Tamil Nadu and Chandigarh respectively but much lower prevalence (3.0\%) in Jharkhand housing majority of labor population. ${ }^{5}$ While slightly lower figures were seen in Gupta et al. (2010), Ahmad et al. (2011) and Majgi SM et al. (2012) among rural population of Tamilnadu (5.9\%), Kashmir (6.05\%) and Puducherry (5.8\%) respectively, may be because of inclusion of lower age group ( $\geq 20$ years). ${ }^{7,8,9}$

Baridalyne et al in 2008 found prevalence of 3.9\% in rural north India may be due to inclusion of younger age group, smaller sample size and study being conducted almost seven years back. ${ }^{10}$ Goa and Karnataka have more diabetic (10.3\% and $10.5 \%$ respectively) in rural areas which could be due to entirely different socio-cultural milieu. ${ }^{11,12} \mathrm{~A}$ rural hospital based study in Haryana reported a very high prevalence $(18.43 \%)$ of Diabetes. ${ }^{13}$

WHO and ADA (American Diabetes Association) follow same fasting blood sugar criteria ( $\geq 126 \mathrm{mg} / \mathrm{dl}$ ) but have different cut-off value for Impaired Fasting Glucose (WHO recommends $>110 \mathrm{mg} / \mathrm{dl}$ whereas ADA's cut-off value for IFG is $>100 \mathrm{mg} / \mathrm{dl}$ ). Thus prevalence of Impaired fasting glucose was found to be $6.4 \%$ using WHO criteria and almost four times (26.6\%) using ADA criteria. Similar prevalence (25.2\%) was found Adopting ADA criteria (25.2\%). ${ }^{14}$

Anjana et al. (2011) reported the prevalence of IFG among 20 years and above as $4.4 \%$ to $4.7 \%$, lower than present study, the prime factor might be inclusion of lower age group. Despite lower age of the subjects ( $\geq 20$ years), they reported higher prevalence from Maharashtra and Chandigarh (7.6 and $10.9 \%$ respectively), which perhaps reflects the variation of sociocultural attributes favoring Diabetes in these states. Vijaykumar et al. (2009) adopting ADA criteria reported a lower prevalence of IFG (5.1\%), but higher prevalence of Diabetes (12.5\%) in rural Kerala. ${ }^{15}$ Higher prevalence (11.1\%) of IFG was reported in Kashmir valley in age group 20-40 year, many of whom might be in early transition phase for becoming diabetic in future. ${ }^{14}$

The present study showed significant increase in prevalence of Diabetes Mellitus (p-0.002) with the age of study subjects, this finding is comparable to other studies. ${ }^{5,8,9,12,16,17}$ There was no diabetic from 30-39 years of age and a small drop reported from 65-70 years, peaks till 60-69 age group. On regression analyses age is found to be significant risk factor similar to Anjana et al. (2011). Males (8.6\%) were more diabetic than females $(5.7 \%)$ but difference is statistically insignificant. Contrary some studies reported a higher prevalence among males. ${ }^{4,12,13}$ However population based multicentric studies NUDS (2001) and PODIS (2004) reported similar prevalence in males and females. ${ }^{18,19}$ But more diabetic females were found by Bhalerao et al. (2014) and Vaz et al. (2011). ${ }^{20,21}$ So conclusive gender wise pattern cannot be established.

Education is not influencing the prevalence of Diabetes. Similar results were obtained from a cohort study among industrial workers by. ${ }^{22}$ In urban India and many western studies had reported lower prevalence of Diabetes among more with educated groups. ${ }^{22,23.24}$ This subtly points towards the different stages of NCD epidemic in which these countries lie- In the west due to better health education the more educated groups have already adopted life style conducive to avert Diabetes whereas, India is lagging behind as low education status may influence the lesser awareness, lesser opportunity for prevention/control, hence it may take a few more decades for India to witness this change.

The present study as in some other studies, ${ }^{9,25,26}$ found occupation to be significantly associated with the prevalence of DM.This association of diabetes with occupation could be due to combined effect of physical activity and work related stress. Then the Prevalence showed a significant difference between class I and class IV and V $(\mathrm{p}=0.04)$. Similarly Vaz et al. (2011) in Goa found highest prevalence in class II while the lowest prevalence upper lower class IV. 


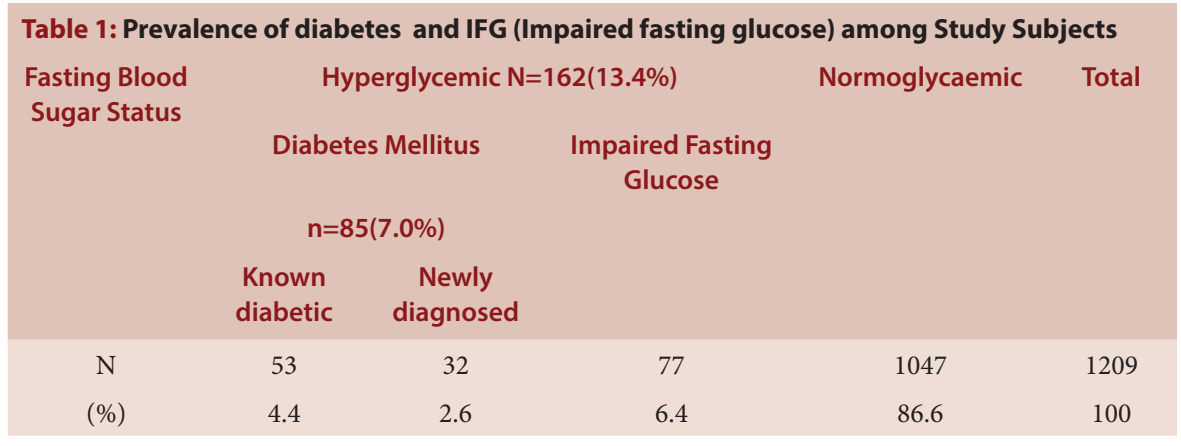

\begin{tabular}{|c|c|c|c|c|c|c|c|}
\hline \multirow[t]{3}{*}{ Age } & \multicolumn{4}{|c|}{ Hyperglycemic } & \multicolumn{2}{|c|}{ Normoglycaemic } & \multirow[t]{3}{*}{ Total } \\
\hline & \multicolumn{2}{|c|}{ Diabetes Mellitus } & \multicolumn{2}{|c|}{$\begin{array}{l}\text { Impaired Fasting } \\
\text { Glucose }\end{array}$} & \multirow[b]{2}{*}{$\mathrm{N}$} & \multirow[b]{2}{*}{$\%$} & \\
\hline & $\mathrm{N}$ & $\%$ & $\mathrm{~N}$ & $\%$ & & & \\
\hline $30-39$ & 0 & 0 & 8 & 2.4 & 322 & 97.6 & 330 \\
\hline $40-49$ & 16 & 5.0 & 24 & 7.3 & 286 & 87.8 & 326 \\
\hline $50-59$ & 32 & 12.1 & 24 & 9.0 & 208 & 78.8 & 264 \\
\hline $60-69$ & 25 & 14.2 & 11 & 6.2 & 140 & 79.6 & 176 \\
\hline$\geq 70$ & 12 & 10.7 & 10 & 8.9 & 91 & 80.6 & 113 \\
\hline Total & 85 & 7.0 & 77 & 6.4 & 1047 & 86.6 & 1209 \\
\hline
\end{tabular}

$\chi^{2}=56.4, \mathrm{df}=4, \mathrm{p}=0.001$

\begin{tabular}{|c|c|c|c|c|c|}
\hline \multirow[t]{2}{*}{ Occupation } & \multirow[t]{2}{*}{$\mathrm{N}$} & \multicolumn{2}{|c|}{ Diabetes Mellitus } & \multicolumn{2}{|c|}{ Impaired Fasting Glucose } \\
\hline & & $\mathrm{n}$ & $\%$ & $\mathrm{n}$ & $\%$ \\
\hline Service/ Professional & 100 & 10 & 10 & 10 & 10.0 \\
\hline Shop-owner/ Business & 31 & 3 & 9.7 & 2 & 6.4 \\
\hline Farmer & 185 & 18 & 9.7 & 6 & 3.2 \\
\hline Laborer & 288 & 12 & 4.1 & 20 & 6.9 \\
\hline Unemployed / Retired & 140 & 12 & 8.5 & 6 & 4.2 \\
\hline Housewife & 465 & 30 & 6.4 & 33 & 7.0 \\
\hline Total & 1209 & 85 & 7.0 & 77 & 6.4 \\
\hline
\end{tabular}

$\chi^{2}=4.74, \mathrm{df}=1, \mathrm{p}=0.029$

\begin{tabular}{|c|c|c|c|c|c|}
\hline \multirow[t]{2}{*}{ Socio-Economic Class } & \multirow[t]{2}{*}{$\mathbf{N}$} & \multirow{2}{*}{$\begin{array}{c}\text { Diabetes } \\
\text { N }\end{array}$} & \multirow{2}{*}{$\begin{array}{c}\text { Mellitus } \\
\%\end{array}$} & \multicolumn{2}{|c|}{ Impaired Fasting Glucose } \\
\hline & & & & $\mathrm{n}$ & $\%$ \\
\hline Upper (I) & 56 & 8 & 14.2 & 4 & 7.1 \\
\hline Upper Middle (II)/Lower Middle (III) & 109 & 6 & 5.5 & 12 & 11.0 \\
\hline Upper Lower (IV)/Lower (V) & 1044 & 71 & 6.8 & 61 & 5.8 \\
\hline Total & 1209 & 85 & 7.0 & 77 & 6.4 \\
\hline
\end{tabular}

$\chi^{2}=4.73, \mathrm{df}=1, \mathrm{p}=0.03$ 


\begin{tabular}{|c|c|c|c|c|}
\hline \multirow[t]{3}{*}{ Age } & \multicolumn{4}{|c|}{ Impaired Fasting Glucose (IFG) } \\
\hline & \multicolumn{2}{|c|}{ WHO } & \multicolumn{2}{|c|}{ ADA } \\
\hline & $\mathbf{N}$ & $\%$ & n & $\%$ \\
\hline $30-39$ & 8 & 2.4 & 60 & 18.1 \\
\hline $40-49$ & 24 & 7.3 & 104 & 31.9 \\
\hline $50-59$ & 24 & 9.0 & 68 & 25.7 \\
\hline $60-69$ & 11 & 6.2 & 51 & 28.9 \\
\hline$\geq 70$ & 10 & 8.8 & 39 & 34.5 \\
\hline Total & 77 & 6.4 & 322 & 26.6 \\
\hline
\end{tabular}

\begin{tabular}{|c|c|c|c|c|c|}
\hline \multirow{2}{*}{$\begin{array}{c}\text { Diabetic status } \\
\text { BMI }\end{array}$} & \multirow[t]{2}{*}{$\mathrm{N}$} & \multicolumn{2}{|c|}{ Diabetes Mellitus } & \multicolumn{2}{|c|}{ Impaired Fasting Glucose } \\
\hline & & $\mathrm{N}$ & $\%$ & $\mathrm{~N}$ & $\%$ \\
\hline$<18.5$ (Underweight) & 319 & 12 & 3.8 & 17 & 5.3 \\
\hline 18.5-24.9(Normal) & 537 & 26 & 4.8 & 20 & 3.7 \\
\hline 25-29.9(Overweight) & 279 & 41 & 14.7 & 22 & 7.9 \\
\hline 30-34.9(Obesity 1) & 64 & 6 & 9.3 & 14 & 21.8 \\
\hline$\geq 35$ (Obesity 2 ) & 10 & 0 & 0 & 4 & 40.0 \\
\hline Total & 1209 & 85 & 7.0 & 77 & 6.4 \\
\hline
\end{tabular}

Fischer test $=35.5, \mathrm{df}=4, \mathrm{p}<0.0001$

\begin{tabular}{|c|c|c|c|c|c|}
\hline \multirow{2}{*}{$\begin{array}{c}\text { Diabetic status } \\
\text { BMI }\end{array}$} & \multirow[t]{2}{*}{$\mathrm{N}$} & \multicolumn{2}{|c|}{ Diabetes Mellitus } & \multicolumn{2}{|c|}{ Impaired Fasting Glucose } \\
\hline & & $\mathrm{N}$ & $\%$ & N & $\%$ \\
\hline <18.5(Underweight) & 319 & 12 & 3.7 & 17 & 5.3 \\
\hline 18.5-22.9(Normal) & 455 & 18 & 3.9 & 20 & 4.3 \\
\hline 23-24.9(Overweight) & 138 & 16 & 11.6 & 4 & 2.8 \\
\hline$\geq 25$ (Obese) & 297 & 39 & 13.1 & 36 & 12.1 \\
\hline Total & 1209 & 85 & 7.0 & 56 & 6.4 \\
\hline
\end{tabular}

$\chi^{2}=32.8, \mathrm{df}=1, \mathrm{p}=0.0001$

\begin{tabular}{|c|c|c|c|c|c|}
\hline \multicolumn{2}{|c|}{$\begin{array}{l}\text { Diabetic status } \\
\text { Waist Circumference }\end{array}$} & \multirow{2}{*}{$\begin{array}{c}\text { Diabetes } \\
\text { Mellitus } \\
24(6.6)\end{array}$} & \multirow{2}{*}{$\begin{array}{c}\begin{array}{c}\text { Impaired } \\
\text { Fasting Glucose }\end{array} \\
11(3.0)\end{array}$} & \multirow{2}{*}{$\begin{array}{l}\text { Normal } \\
\text { 331(90.4) }\end{array}$} & \multirow{2}{*}{$\begin{array}{l}\text { Total (\% } \\
366(67.0\end{array}$} \\
\hline \multirow{3}{*}{ Males } & Normal & & & & \\
\hline & High & 23(12.8) & $20(9.0)$ & $137(76.2)$ & $180(33.0)$ \\
\hline & Total & $47(8.6)$ & $31(5.6)$ & $468(85.8)$ & $546(100)$ \\
\hline \multirow[t]{3}{*}{ Females } & Normal & $4(1.3)$ & $14(4.8)$ & 276(93.9) & $294(44.3)$ \\
\hline & High & $34(9.2)$ & $32(8.7)$ & $303(82.1)$ & $369(55.7)$ \\
\hline & Total & $38(5.7)$ & $46(7.2)$ & $579(87)$ & $663(100)$ \\
\hline
\end{tabular}

Male $(\mathrm{p}=0.005)$, Female $(\mathrm{p}=0.0001)$ 


\begin{tabular}{|c|c|c|c|c|c|}
\hline \multicolumn{2}{|c|}{$\begin{array}{c}\text { Diabetic status } \\
\text { WHR }\end{array}$} & \multirow{2}{*}{$\begin{array}{l}\text { Diabetes Mellitus } \\
\qquad 4(2.4)\end{array}$} & \multirow{2}{*}{$\begin{array}{l}\text { Impaired Fasting } \\
\text { Glucose } \\
5(3.0)\end{array}$} & \multirow{2}{*}{$\begin{array}{l}\text { Normal } \\
\text { 155(94.6) }\end{array}$} & \multirow{2}{*}{$\begin{array}{l}\text { Total (\%) } \\
164(30.0)\end{array}$} \\
\hline & Normal & & & & \\
\hline Males & High & $43(11.2)$ & $26(6.8)$ & $303(79.0)$ & $382(70.0)$ \\
\hline \multirow{4}{*}{ Females } & Total & $47(8.6)$ & $31(5.6)$ & $468(85.7)$ & $546(100)$ \\
\hline & Normal & $0(0)$ & $4(4.7)$ & $80(14.0)$ & $84(13.0)$ \\
\hline & High & $38(6.6)$ & $42(7.2)$ & $499(86.0)$ & $579(87.0)$ \\
\hline & Total & $38(5.7)$ & $46(7.0)$ & $579(87.3)$ & $663(100)$ \\
\hline
\end{tabular}

Fisher test $=12.7 \mathrm{df}=1 \quad \mathrm{p}=0.0001 \quad$ Fisher test $=6.03 \mathrm{df}=1 \quad \mathrm{p}=0.014(? ?)$

$\begin{array}{ccccc}\begin{array}{c}\text { Table 10: Association of Hypertension and Diabetes Mellitus in Study Subjects } \\ \text { Diabetic status } \\ \text { Blood Pressure }\end{array} & \begin{array}{c}\text { Diabetes Mellitus } \\ \text { Impaired Fasting } \\ \text { Glucose }\end{array} & \text { Normal } & \text { Total (\%) } \\ \text { Normal } & 16(18.8) & 27(35.0) & 473(47.2) & 516(42.7) \\ \text { Pre-hypertension } & 27(31.8) & 32(41.6) & 378(36.1) & 437(36.1) \\ \text { Hypertension } & 42(49.4) & 18(23.4) & 196(18.7) & 256(21.2) \\ \text { Total } & 85(100) & 77(100) & 1047(100) & 1209(100)\end{array}$

$\chi^{2}=45.0 \quad$ df $-1 \quad$ p-value $=0.00001$

\begin{tabular}{|c|c|c|c|c|c|}
\hline \multirow[t]{2}{*}{ Physical Activity } & \multirow[t]{2}{*}{$\mathrm{N}$} & \multicolumn{2}{|c|}{ Diabetic } & \multicolumn{2}{|c|}{ Impaired Fasting Glucose } \\
\hline & & $\mathbf{N}$ & $\%$ & $\mathrm{~N}$ & $\%$ \\
\hline Low & $412(34.0)$ & 44 & 10.7 & 29 & 9.4 \\
\hline Moderate & $616(51.0)$ & 33 & 5.3 & 41 & 6.6 \\
\hline Vigorous & $181(15.0)$ & 8 & 4.4 & 7 & 3.8 \\
\hline Total & $1209(100)$ & 85 & 7.0 & 77 & 6.4 \\
\hline
\end{tabular}

$\chi^{2}=12.7 \mathrm{df}=1 \quad \mathrm{p}=0.001$

\begin{tabular}{|c|c|c|c|c|}
\hline \multirow[t]{2}{*}{ Variable } & \multirow{2}{*}{$\begin{array}{l}\text { Odds } \\
\text { ratio }\end{array}$} & \multicolumn{2}{|c|}{$\mathrm{Cl}(95 \%)$} & \multirow{2}{*}{$p$-value } \\
\hline & & Lower & Upper & \\
\hline WHR & 2.780 & 1.490 & 5.188 & 0.001 \\
\hline Age & 1.984 & 1.193 & 3.298 & 0.008 \\
\hline BMI & 1.797 & 1.070 & 3.020 & 0.027 \\
\hline Hypertension & 1.752 & 1.032 & 2.973 & 0.038 \\
\hline Physical activity & 0.623 & 0.385 & 1.008 & 0.054 \\
\hline Family History & 2.158 & 0.820 & 5.680 & 0.119 \\
\hline WC & 1.394 & 0.699 & 2.782 & 0.346 \\
\hline
\end{tabular}


Early diagnosis and treatment is important to reduce morbidity and mortality in non-communicable diseases. Diagnostic gap of $37 \%$ was calculated (Prevalence of diabetes mellitus was $7 \%$, of these $2.6 \%$ are newly diagnosed while the remaining are known diabetic). Ahmad et al. (2011) and Deepthi R et al. (2013) found a gap of 33\% and 46\%. Anjana et al. (2011) multicentric study reported diagnostic gap of more than $50 \%$ perhaps due to larger sample size of study.,12,18

Insight into risk factors is important for the prevention. The present study showed that BMI is a significant independent predictor of development of diabetes. It also supported the evidence that among Asians, even at lower BMI, there were higher odds (3.8) of diabetes and the prevalence shows a marked difference among those having high BMI (12.6\%) as compared to those having normal BMI (3.8\%). WHR an index of central obesity was significantly associated with increase in prevalence of DM. Prevalence of diabetes mellitus is also found to increase with increasing WHR and WC. Chances of having diabetes mellitus are found to be 2.8(odds ratio) times and 5.8 (odds ratio) times higher respectively with higher WC and WHR which in conformity with the study of Ohlson et al and Rathod et al (2014). Some other studies also found similar findings in relation to age, BMI, WHR, WC. ${ }^{26,27}$ Ahmad et al (2011) stated that evidences both from prospective and cross-sectional studies suggest obesity to be strongly linked to Diabetes.

Prevalence of diabetes decreased significantly from $10.7 \%$ among those with low physical activity to $4.4 \%$ among those having vigorous activity. Kokiwar et al. (2007) and Majgi et al. (2012) reported same in rural Maharashtra and Puducherry. ${ }^{9,28}$ Contrary Raghupathy et al. (2007) in rural Vellore found no association, the difference obviously is because of younger study subjects (26-32 years)-an age not prone to become diabetics. ${ }^{29}$ However this significance faded under multivariate analysis $(\mathrm{p}=0.054)$ (odd's ratio is 0.6$)$ reflecting physical activity is not an independent risk factor for diabetes mellitus.

The present study depicts that Hypertension is significantly associated with Type II Diabetes mellitus. Around $49 \%$ of diabetic are hypertensive, $31.8 \%$ prehypertensive and only $18 \%$ were normotensive. Odds of having hypertension among Diabetic is calculated as 1.72 thus depicting higher chances of hypertension in diabetics. Anjana et al. (2011) and some other studies also alarmed hypertension as important risk factor. ${ }^{25,30,31}$ However, with IFG no such association was observed.

Asian Indians have an ethnic susceptibility to Type II diabetes and a high familial aggregation of the disease. Similarly present study showed significantly higher prevalence of diabetes among those with positive family history (40\%) as compared to those with no family history (6.7\%). Odds of diabetes with family history are 3.2-times compared those without family history of diabetes. Ramachandran A et al. (2001) Vaz et al. (2011) and B. Valliyot et al. (2013) also found significant association with family history. ${ }^{19,21,25}$ Unhealthy eating contributes largely to obesity. According to WHO diets consumed in South East region typically energy dense, high in saturated fatty acids and low in fruits and vegetables, which are established risk factor for the development of type II diabetes mellitus. But no association was found with servings of fruits and vegetables also same fining by B. Valliyot et al. (2013) in his case control study.

Study is limited by sample size as number of villages selected may not represent total population. The confounding variables whether known or not known are inevitable in any analytical study. A possibility of recall bias in the family history of diabetes cannot be ruled out due to the inadequate literacy levels of the rural population.

\section{CONCLUSION}

As evident from findings diabetes is becoming common in rural population also, adding to the problem is poor awareness. Health care systems should be strengthened for early detection and effective treatment of disease. NPCDCS (National program for control of diabetes, cancer and stroke) has focused on awareness generation for behavior and lifestyle changes, screening and early diagnosis, treatment and referral to higher facilities for appropriate management for non-communicable diseases (recently ASHA is being deployed for the screening of diabetes and hypertension).

WHO calls for multi-sectoral, population-based approaches to help reduce risk factors for diabetes in the general population and recommends healthy eating and physical activity from an early age to prevent type 2 diabetes later in life. Importantly, regulation of marketing, trade and agricultural policies to promote healthier eating is also proposed. Prevention is of utmost importance, but for the millions of diabetics managing their disease must remain the priority. WHO's report recommends a multidisciplinary approach with patient education, medication, and consistent follow- up.

\section{ACKNOWLEDGEMENT}

The authors would like to thank all participants in this study.

\section{CONFLICTING INTEREST}

$\mathrm{Nil}$

\section{ABBREVIATION USED}

BMI: Body mass index; WHR: Waist Hip ratio; WC: Waist circumference; IFG: Impaired Fasting Glucose; ADA: American diabetes association.

\section{REFERENCES}

1. Algaonker SS. Diabetes mellitus as seen in Ancient Ayurvedic Medicine. In Bajaj AS, editor. Insulin and Metabolism. Bombay (India): Indian Press 1972.

2. West KM. Epidemiology of diabetes and its vascular lesions. Elsevier, New York, 1978.

3. Worldwide trends in diabetes since 1980: a pooled analysis of 751 populationbased studies with 4.4 million participants. 2016;387(10027):1513-30.

4. Misra A, Shrivastava U. Obesity and dyslipidemia in South Asians. Nutrients. 2013;5(7):2708-33.

5. Anjana RM et al. Prevalence of diabetes and prediabetes (impaired fasting glucose and/or impaired glucose tolerance) in urban and rural India: phase I results of the Indian Council of Medical Research-INDIA Diabetes (ICMR-INDIAB) study. Diabetologia. 2011;54(12):3022-7.

6. Prevalence of Diabetes and Pre-Diabetes in India: ICMR - INDIAB study, 2011

7. Gupta SK, Singh Z, Purty AJ, Kar M, Vedapriya DR, Mahajan P, et al. Diabetes prevalence and its risk factors in rural area of Tamil Nadu. Indian $\mathrm{J}$ Community Med. 2010;35(3):396-9.

8. Javid A, Muneer AM, Mohd A, Rauf R, Rafiq A, Ashfaq A, et al. Prevalence of Diabetes Mellitus and Its Associated Risk Factors in Age Group of 20 Years and Above in Kashmir. India Al Ameen J Med Sci. 2011;4(1):38-44.

9. Majgi SM, Soudarsan BM, Roy G, Das AK. Risk Factors of Diabetes Mellitus in Rural Puducherry. Online J Health Allied Scs. 2012;11(1):4.

10. Nongkynrih B, Acharya A, Ramakrishnan L, Ritvik, Anand K, Shah B. Profile of biochemical risk factors for non-communicable diseases in urban, rural and periurban Haryana. India J Assoc Physicians India. 2008;56:165-170.

11. Vaz NC, Ferreira AM, Kulkarni MS, Vaz FS, Pinto NR. Prevalence of diabetic complications in rural Goa, India. Indian J Community Med. 2011;36(4):283-6.

12. Deepthi R, Chandini $C$, Pratyusha K. Screening for Diabetes and their risk factors among adults in Rural Kolar. A Community Based Study Int J Res Dev Health. 2013;1(4):152-9

13. Himanshu M, Poonam A, Renu G, Ashuma S, Surajeet KP, Rajesh N. Prevalence of diabetes mellitus in rural population of district Sonepat India. Int J Med Sci Public Health. 2014;3(3):261-4

14. Zargar AH, Wani AA, Laway BA, Masoodi SR, Wani Al, Bashir MI, et al. Prevalence of diabetes mellitus and other abnormalities of glucose tolerance in young adults aged $20-40$ years in North India (Kashmir Valley). Diabetes Res Clin Pract. 2008; 82(2):276-81.

15. Vijayakumar G, Arun R, Kutty VR. High prevalence of type 2 diabetes mellitus and other metabolic disorders in rural Central Kerala. J Assoc Physicians India. 2009;57(2):563-7. 
16. Ramachandran A, Mary S, Yamuna A, Murugesan N, Snehalatha C. High prevalence of diabetes and cardiovascular risk factors associated with urbanization in India. Diabetes Care. 2008;31(5):893-8.

17. Basavana GH, Prabhakar A, Prasannaraj P et al. Study of prevalence of diabetes mellitus and impaired fasting glucose in a rural population. International Journal of Diabetes in Developing Countries. 2005;25:98-101.

18. Sadikot SM, Nigam A, Das S, Bajaj S, Zargar AH, Prasannakumar KM, et al. The burden of diabetes and impaired glucose tolerance in India using the WHO 1999 criteria: prevalence of diabetes in India study (PODIS). Diabetes Res Clin Pract. 2004;66:301-7.

19. Ramachandran A, Snehalatha C, Kapur A. Diabetes Epidemiology Study Group in India (DESI). High prevalence of diabetes and impaired glucose tolerance in India: National Urban Diabetes Survey. Diabetologia. 2001;44(9):1094-101.

20. Sanjay DB, Manjunath S, Sunil SV, Rajashree R, Shivprasad SG. Risk factor for type 2 diabetes mellitus in rural population of north Karnataka: A community based cross sectional study. Int J Pharm Med Bio. 2014;3(1):1-14.

21. Vaz NC, Ferreira AM, Kulkarni MS, Vaz FS, Pinto NR. Prevalence of diabetic complications in rural Goa, India. Indian J Community Med. 2011;36(4):283-6.

22. Prabhakaran D, Shah P, Chaturvedi V, Ramakrishnan L, Manhapra A, Reddy KS. Cardiovascular risk factor prevalence among men in a large industry of northern India. Natl Med J India. 2005;18(2):59-65.

23. Laramee AS, Morris N, Littenberg B. Relationship of literacy and heart failure in adults with diabetes. BMC Health Services Research. 2007;7(1):98.

24. Gholamreza V, Mehdi S, Hamidreza J, Sed AH, Farhad N. Association between socio-demographic factors and diabetes mellitus in the north of Iran: A population-based study. International Journal of Diabetes Mellitus. 2010;3(2):154-7.

25. Balakrishnan V, Jayadevan S, Jayakumary M, Sudha BV. Risk factors of type 2 diabetes mellitus in the rural population of north Kerala, India: A case control study. Diabetologia Croatica. 2013;42-1.

26. Sayeed M, Mahtab H, Khanam P, Latif Z, Ali SM, Akhtar B, et al. Diabetes and Impaired Fasting Glycemia in a Rural Population of Bangladesh. Diabetes Care. 2003;26(4):1034-9.

27. Vazquez G, Duval S, Jacobs DR, Silventoinen K. Comparison of body mass index, waist circumference, and waist/hip ratio in predicting incident diabetes: a meta-analysis. Epidemiological Reviews. 2007;29(1):115-28.

28. Kokiwar P, Gupta S, Durge P. Prevalence of diabetes in a rural area of central India. International Journal of Diabetes in Developing Countries. 2007;27(1):8-10.

29. Raghupathy P, Antonisamy B, Fall C, et al. High prevalence of glucose intolerance even among young adults in south India. Diabetes Research Clinical Practice. 2007;77(2):269-79.

30. Mohammed S, Shruti D, Cletus J. D'Souza M, Xaviour D, Raviprasad BV. Impact of Hypertension on Type 2 Diabetes in Mysore Population of South India. International Journal of Clinical Medicine. 2013;4(12):561-70.

31. Radhakrishnan S, Balamurugan S. Prevalence of diabetes and hypertension among geriatric population in a rural community of Tamil Nadu. Indian J Med Science. 2013;67:130-6

Cite this article : Agarwal V, Singh G, Misra SK. Diabetes Sweeping Rural Areas: Findings from Community Based Study in Rural Agra, India. Int J Med Public Health. 2017;7(4):207-13. 